\title{
Reforming the Pay-As-You-Go Pension System: Who Votes for it? When?
}

\section{GEORGES CASAMATTA AND JOÃO GONDIM}




\title{
Reforming the Pay-As-You-Go Pension System: Who Votes for it? When?*
}

\author{
Georges Casamatta ${ }^{\dagger}$ and João Gondim ${ }^{\ddagger}$
}

October 2009

\begin{abstract}
We assess the political support for parametric reforms of the Pay-As-You-Go pension system following a downward fertility shock. Using a continuous time overlapping generations model, we argue that reforms that consist in cutting pension benefits or increasing the retirement age are likely to receive a strong political support. An increase in the contribution rate has, on the contrary, fewer chances to be approved by the majority of the voters. This framework also allows to identify the costs and benefits of postponing each type of reform and to determine how the timing of the different reforms affects their political support.
\end{abstract}

Keywords: Pay-As-You-Go, parametric reforms, fertility shock.

*This research has benefitted from the financial support of the ANR "Retraite" (ANR-05-BLAN0020). We thank Vladimir Borgy, Friedrich Breyer, Devis Geron and Pierre Pestieau for their comments as well as participants to the 2008 ENTER Jamboree (UCIII-Madrid), the IIPF (Maastricht, 2008) and ESEM (Milan, 2008) conferences and the "atelier Retraites" 2008 (Caisse des Dépôts et Consignations, Bordeaux).

${ }^{\dagger}$ Toulouse School of Economics (GREMAQ-CNRS), email: georges.casamatta@univ-tlse1.fr

${ }^{\ddagger} \mathrm{ESAF}$ (Brazil) and Toulouse School of Economics, e-mail: jlgondim@terra.com.br 


\section{Introduction}

Our societies are becoming older and older. As reported by Gruber and Wise (1998), the ratio of individuals above 65 over individuals aged between 20 and 64 will approximately double from year 2000 to 2050 in most developed countries. The sources of population aging lie in two demographic phenomena: rising life expectancy and declining fertility. For almost eighty years, fertility rates have been declining in both Europe and the US. This drop has been quite dramatic, falling from around 3 children per woman in 1920 or 1930 to the current levels of 1.2 to 2 children per woman, depending on the country. This decline has not however been steady over time. In the post world war II period, fertility rates have been increasing suddenly in all industrialized countries (baby boom) and have started to fall again in the mid 60s. Since the beginning of the 80s, fertility rates has been more or less stable (Boldrin et al. (2005)).

This demographic trend puts an increasing pressure on the financial viability of PayAs-You-Go (PAYG) systems: for given parameters of the system, there are not enough contributors to finance the pensions of the baby-boomers. These systems thus need to be reformed. We consider in this paper parametric reforms of the PAYG system, that consist in adjusting its key parameters. To deal with population aging, one can raise the contribution rate, decrease the level of benefits and/or increase the retirement age. As argued by Cremer and Pestieau (2000), this problem is mainly political. Any reform induces some conflicts of interest between generations. Old workers and retirees prefer to raise taxes rather than to cut benefits whereas young workers have opposite preferences. The retirees favor an increase in the retirement age, as they benefit from this change but do not support its cost, whereas some workers may oppose it. In these circumstances, how will these conflicts be resolved? How will the burden of the demographic transition be shared among the different generations?

Our aim is to provide some elements of answer to these questions. We consider a society that faces a downward fertility shock in a given period and needs to adjust its PAYG system to maintain its financial viability. Individuals are identical in all respects, except for their age. During working life, they contribute to the pension system. After retirement, they receive a pension benefit. We assume no savings, so that pensions is the only source of income for a retiree. The government also collects a lump-sum tax on all 
individuals, workers and retirees, that can be used to restore the balance of the PAYG budget.

Section 3 determines the preferences of the citizens with respect to the pension system in the steady state before the demographic shock. The optimal contribution rate of the workers is increasing with age and the retirees want the tax rate to be as high as possible. This result was first established by Browning (1975) and is by now standard in the literature on the political economy of pensions (see for example Sjoblom (1985)). We also determine the optimal retirement age among different age groups. We show that it is constant until a threshold age and then equal to the age of the individual considered.

Section 4 addresses the demographic transition. In a first step, we determine the values of the income taxes needed to balance the government budget constraint when no parameter of the pension system is altered. This situation is referred to as the no reform case, or status quo. As the ratio of the number of workers to the number of retirees is decreasing over time, these taxes should increase with time.

We next consider reforms of the PAYG system (taking place simultaneously to the fertility shock) and first compare a marginal increase in the contribution rate with a marginal cut in benefits. We show that, when there is perfect consumption smoothing in the steady state before the shock and the coefficient of relative risk aversion is below 1 , the steady state decisive voter prefers to cut benefits rather than to increase the contribution rate. When this latter is older than the median age individual, the majority of the voters hold the same preferences. The intuition behind this result is that, even though it yields a decrease in lifetime income, a drop in benefit leads to a repartition of lifetime income along the life-cycle that is more in line with the individuals' preferences.

The previous results concerned the reform of the payroll tax rate or the benefit level. What about raising the retirement age? It turns out that, with perfect consumption smoothing in the steady state, the decisive voter in this steady state votes for this reform, when compared to the status quo. Here again this means that it is likely to receive a strong political support. The numerical simulations presented in section 5 confirm this finding. They also show that increasing the retirement age is majority preferred to the other two reforms (cut in benefits and increase in the contribution rate) for a large set of parameter values. 
The reforms just described were assumed to take place contemporaneously to the shock. We envisage in subsection 4.4 the possibility to defer the reform to a later date. We find that delaying the reform has two effects, of opposite direction. On the one hand, it changes the age of the individuals indifferent between implementing the reform or not. As time goes on, older people starts favoring a cut in benefits. This makes the political support for reducing pension benefits increase over time. On the other hand, those people who support this reform are the younger ones. Due to population ageing, their proportion is decreasing with time, leading to a lower political support. The way the political support for a reform evolves over time thus depends on the comparison of these two effects.

\section{Related Literature}

There exists a large literature, starting from Browning (1975) and surveyed in Galasso and Profeta (2002), that study analytically the majority voting determination of PAYG pension systems in the steady state.

Most of the studies that address the problem of social security reform are based on calibrated quantitative models in which the welfare effects of different reforms are calculated (see, among others, Conesa and Krueger (1999), Conesa and Garriga (2008a, 2009b), De Nardi et al. (1999), Nishiyama and Smetters (2007)). Moreover, these articles often focus on the transition to a fully funded system.

To our knowledge, the only papers that approach this question from an analytical standpoint are Breyer and Stolte (2001) and Gonzalez-Eiras and Niepelt (2008). Breyer and Stolte (2001) show that, when taxation is distortionary (endogenous labor supply), pensioners share the burden of the demographic change with the workers, meaning that pension benefits are decreased. Gonzalez-Eiras and Niepelt (2008) consider a two-period dynamic probabilistic voting model with logarithmic utility. Their main findings are that population ageing should lead to higher contribution tax rates and a larger share of pensions in GDP. 


\section{The model}

\subsection{Timeline and demographics}

The model is a continuous time overlapping-generations model where each agent lives for an interval of size $l$. His life is divided between working life, from birth to age $a$, and retirement life, from age $a$ to death at age $l$.

At a given point in time $t$, retirees comprehend the group of people older than $a$, those born from $t-l$ to $t-a$, and workers are those younger than $a$, those born from $t-a$ to $t$. We denote $N_{t}^{r}$ the number of retirees and $N_{t}^{w}$ the number of workers, both at time $t$.

\section{$2.2 \quad$ Wages and taxes}

All workers receive the same wage, normalized to one. They pay two types of taxes: a linear contribution rate $\tau$ to finance the PAYG pension system and an income tax $T$ to the general government budget. The difference between these two taxes is that only the workers contribute to the pension system, whereas both the workers and the retirees pay the income tax. The proceeds of the income tax are used to complement the financing of pension benefits when the PAYG's budget is in deficit. This assumption accounts for the supplementary role that general government revenues play on the financing of pensions. It will also be useful to allow some imbalancement in PAYG budget before reform takes place, enabling the model to study the timing of the reform. Consumption at date $t$ is thus $c_{t}^{w}=1-\tau_{t}-T_{t}$ for a worker and $c_{t}^{r}=b_{t}-T_{t}$ for a retiree where $b_{t}$ stands for pension benefits.

\section{$2.3 \quad$ Preferences}

The unique heterogeneity among agents is their birth date. The monetary disutility from working is assumed constant ${ }^{1}$ and denoted by $\gamma$. Instantaneous utility of consumption

\footnotetext{
${ }^{1}$ One could alternatively assume that the disutility from working is increasing with age. Although this is likely to be true for manual workers, it is not so likely for intellectual workers: professors, administrators, ... One could also argue that the utility of leisure is decreasing with age: free time is worth more when younger. What matters for retirement decision is the difference in utility levels when working with respect to when retired, and this difference may be increasing, constant or decreasing depending on the which effect dominates: the (possibly) increasing disutility from work or the decreasing utility of leisure. This paper takes no side in this discussion and assumes that the parameter $\gamma$ that captures this difference is constant.
} 
$u(c)$ is assumed continuous, twice differentiable and strictly concave.

The life-cycle utility of a worker and a retiree aged $x$ at time $t$ are respectively given by

$$
U_{t}^{w}(x) \equiv \int_{t}^{t+a-x} e^{-\beta(v-t)}\left(u\left(1-\tau_{v}-T_{v}\right)-\gamma\right) d v+\int_{t+a-x}^{t+l-x} e^{-\beta(v-t)} u\left(b_{v}-T_{v}\right) d v
$$

and

$$
U_{t}^{r}(x) \equiv \int_{t}^{t+l-x} e^{-\beta(v-t)} u\left(b_{v}-T_{v}\right) d v
$$

where $\beta$ is the discount factor.

\subsection{Resource constraint}

The Government Budget Constraint (GBC) at any time $t$ is

$$
N_{t}^{r} b_{t}=N_{t}^{w} \tau_{t}+\left(N_{t}^{w}+N_{t}^{r}\right) T_{t}
$$

Equation (3) states that PAYG benefits (left hand side) must be completely financed from the proceeds of the PAYG contribution rate plus transfers from the general government budget at each time $t$ (right hand side). Note that the workers pay the contribution rate $\left(\tau_{t}\right)$ and the income tax $\left(T_{t}\right)$ while the retirees pay only the latter.

Assumption 1 No deficit on PAYG budget in the initial steady state.

This assumption implies that, in the steady state before the fertility shock, there is no need to supplement PAYG revenues with transfers from the general government budget: $T_{t}=0$. The government budget constraint in the steady state before the shock is thus

$$
N_{t}^{r} b_{s s}=N_{t}^{w} \tau_{s s}
$$

where $b_{s s}$ and $\tau_{s s}$ are the benefit level and the contribution rate in the steady state respectively. Equation (5) below gives the well known formula that pension benefit is the product of the contribution rate times the inverse of the dependency rate $^{2}$ when the PAYG budget is balanced:

$$
b_{s s}=\tau_{s s} \rho_{s s}(n, a, l),
$$

\footnotetext{
${ }^{2}$ The dependency rate is defined as the ratio of the number of retirees to the number of workers, $N_{t}^{r} / N_{t}^{w}$.
} 
where

$$
\rho_{s s}=\frac{N_{t}^{w}}{N_{t}^{r}}=\frac{\int_{t-a}^{t} e^{n s} d s}{\int_{t-l}^{t-a} e^{n s} d s}=\frac{1-e^{-n a}}{e^{-n a}-e^{-n l}}=e^{n l} \frac{e^{n a}-1}{e^{n l}-e^{n a}} .
$$

The dependency rate (and its inverse $\rho$ ) depends on the fertility rate $(n)$, total lifetime $(l)$ and on the size of working life $(a)$. The fertility rate and total lifetime are exogenous demographic parameters while the size of working life is an endogenous parameter of the PAYG system.

\section{$3 \quad$ Initial steady state}

In the initial steady state, the rate of population growth is constant and equal to $n$. The PAYG system in this steady state is characterized by the triplet $\left(\tau_{s s}, b_{s s}, a_{s s}\right)$, chosen through the political process. We make no specific assumption about this political process. We simply assume that the pension system in the steady state is optimal for some individual, of age $x_{d}$.

We study in the next section the reform of the system following a negative fertility shock. But before, we describe the preferences of the different individuals on the contribution rate and the benefit level in the initial steady state.

\subsection{Optimal contribution rates}

Using (2), the retirees optimal contribution rate is given by the following program:

$$
\max _{\tau \in[0,1]} U_{s s}^{r}(x) \equiv \int_{t}^{t+l-x} e^{-\beta(v-t)} u\left(\rho_{s s} \tau\right) d v,
$$

where the pension benefit given by the steady state resource constraint (5) is already substituted into the objective function. Since they do not contribute to PAYG anymore, the preferred contribution rate of the retirees is the maximal one $(\tau=1)$.

Using (1), the workers optimal contribution rate solves:

$$
\max _{\tau \in[0,1]} U_{s s}^{w}(x) \equiv \int_{t}^{t+a-x} e^{-\beta(v-t)}(u(1-\tau)-\gamma) d v+\int_{t+a-x}^{t+l-x} e^{-\beta(v-t)} u\left(\rho_{s s} \tau\right) d v
$$


The relationship of optimal tax rates with respect to age is described in the following proposition.

Proposition 1 The preferred contribution rate is strictly increasing in worker's age and it is maximal for retirees:

$$
\tau_{s s}^{*}(x) \begin{cases}\text { is strictly increasing in } x & , \text { if } x \in[0, a) \\ =1 & , \text { if } x \in[a, l] .\end{cases}
$$

Proof. The program of the workers (8) can be written:

$$
\max _{\tau}\left(-\frac{1}{\beta}\left(e^{-\beta(a-x)}-1\right)\right)(u(1-\tau)-\gamma)+\left(-\frac{1}{\beta}\left(e^{-\beta(l-x)}-e^{-\beta(a-x)}\right)\right) u\left(\rho_{s s} \tau\right)
$$

which first-order condition is

$$
\left(e^{-\beta(a-x)}-1\right) u^{\prime}\left(1-\tau_{s s}^{*}\right)-\left(e^{-\beta(l-x)}-e^{-\beta(a-x)}\right) \rho_{s s} u^{\prime}\left(\rho_{s s} \tau_{s s}^{*}\right)=0 .
$$

Applying the implicit function theorem gives

$$
\frac{d \tau_{s s}^{*}}{d x}=\frac{\beta e^{-\beta(a-x)} u^{\prime}\left(1-\tau_{s s}^{*}\right)-\beta\left(e^{-\beta(l-x)}-e^{-\beta(a-x)}\right) \rho_{s s} u^{\prime}\left(\rho_{s s} \tau_{s s}^{*}\right)}{\left(e^{-\beta(a-x)}-1\right) u^{\prime \prime}\left(1-\tau_{s s}^{*}\right)+\left(e^{-\beta(l-x)}-e^{-\beta(a-x)}\right) \rho_{s s}^{2} u^{\prime \prime}\left(\rho_{s s} \tau_{s s}^{*}\right)}>0 .
$$

This proposition is a generalization of the result already established in the literature for the three-periods overlapping generations case. ${ }^{3}$ Older workers maximize over a reduced horizon, since they do not take into account their past contributions in their optimization problem. In other words, the PAYG return increases with worker's age, since its benefit is the same for all agents, but its cost is decreasing with age.

The profile of optimal contribution rates is represented on the figure below.

\subsection{Optimal retirement ages}

The preferred retirement age of an individual aged $x, a_{s s}^{*}(x)$, maximizes his remaining lifetime utility. This choice implies that the agent will be a worker, when $x<a_{s s}^{*}$, or a retiree, when $x \geq a_{s s}^{*}$. When making his choice, the agent must take into account that this retirement age will be mandatory to everyone in the PAYG system: a higher retirement age yields a smaller dependency ratio. ${ }^{4}$ The optimal retirement age is thus

\footnotetext{
${ }^{3}$ See Browning (1975) or Sjoblom (1985).

${ }^{4} \rho_{s s}(a)$, defined in (6), is strictly increasing in $a$, with $\rho_{s s}(0)=0$ and $\lim _{a \rightarrow l} \rho_{s s}(a)=+\infty$.
} 


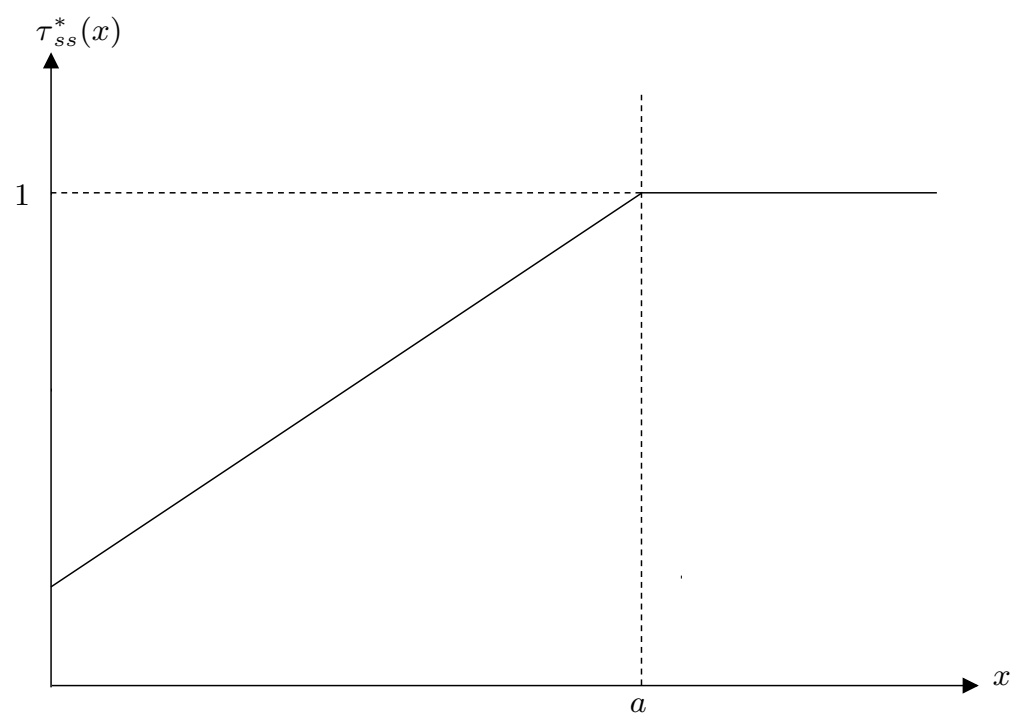

Figure 1: Preferences over the contribution rate by age cohort

$$
a_{s s}^{*}=\arg \max \left\{\left[\begin{array}{c}
\max _{a} U_{s s}^{w}(x) \\
\text { s.t. } a>x
\end{array}\right],\left[\begin{array}{c}
\max _{a} U_{s s}^{r}(x) \\
\text { s.t. } a \leq x
\end{array}\right]\right\}
$$

If an agent aged $x$ prefers to be retired, then he maximizes $U_{s s}^{r}(x)$ (given in (7)) with respect to $a$, subject to $a \leq x$. The solution to this problem is $a_{s s}^{*}(x)=x$. In words, he chooses the highest retirement age such that he is retired. On the one hand, choosing $a_{s s}^{*}>x$ would violate the maximization constraint. On the other hand, choosing $a_{s s}^{*}<x$ would decrease the pension benefit since there would be more retirees to divide PAYG revenues and less workers to finance it.

If an agent aged $x$ prefers to be a worker, then he maximizes $U_{s s}^{w}(x)$ (given in (8)) with respect to $a$, subject to $a>x$. Denoting $\widetilde{a}$ the solution to this program, the first-order condition on $\widetilde{a}$, taking into account the impact of a higher retirement age on the inverse of the dependency rate, is given by:

$$
\begin{aligned}
& e^{-\beta(\widetilde{a}-x)}\left(u(1-\tau)-\gamma-u\left(\rho_{s s} \tau\right)\right)-\frac{1}{\beta}\left(e^{-\beta(l-x)}-e^{-\beta(\widetilde{a}-x)}\right) u^{\prime}\left(\rho_{s s} \tau\right) \tau \frac{\partial \rho_{s s}}{\partial a}=0 \\
\Leftrightarrow & \left(u(1-\tau)-\gamma-u\left(\rho_{s s} \tau\right)\right)-\frac{1}{\beta}\left(e^{-\beta(l-\widetilde{a})}-1\right) u^{\prime}\left(\rho_{s s} \tau\right) \tau \frac{\partial \rho_{s s}}{\partial a}=0 .
\end{aligned}
$$

The first two terms capture the effect of a marginal increase in working life and the third term corresponds to the marginal decrease in retirement life. The last term captures 


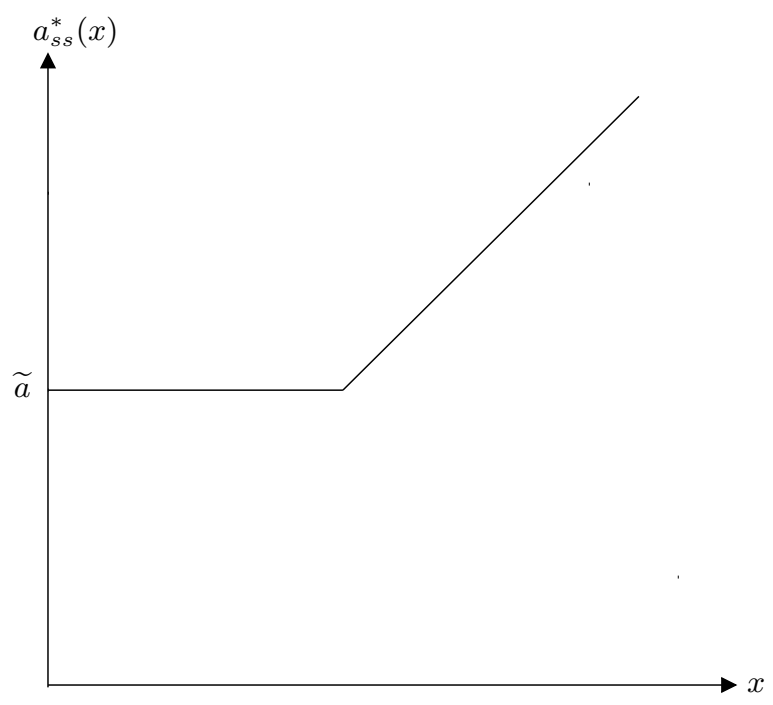

Figure 2: Optimal retirement ages in the steady state

the impact of a higher retirement age on the level of pension benefits. This term is not usually acknowledged in the endogenous retirement literature (Crawford and Lilien (1981), Sheshinski (1978)) because this latter deals with the individual choice on retirement age, not extensible to the other agents in the pension system. Here, the retirement age is applicable to all agents within the pension system. Lacomba and Lagos (2007) name this effect of a higher retirement age on the value of pension benefits as the macro effect. This effect is positive, implying that $u\left(1-\tau_{s s}\right)-\gamma<u\left(b_{s s}\right)$. In words, agents get an increase in utility when they retire.

Observe that condition (11) does not depend on $x$. This means that all the individuals who choose to be workers have the same optimal retirement age.

The results concerning the preferences over the retirement age in the steady state before the shock are summarized in the proposition below.

Proposition 2 For a given payroll tax rate, the preferred retirement age of individuals younger than $\widetilde{a}$ is $\widetilde{a}$. The preferred retirement age of an individual aged $x$, with $x \geq \widetilde{a}$ is $x$.

The profile of preferred retirement ages is represented on figure 2 .

In the remainder of the paper, we shall assume that $a_{s s}=\widetilde{a}$, meaning that the decisive voter in the steady state, $x_{d}$, is younger than $\widetilde{a}$. 


\section{Adjustment to the fertility shock}

\subsection{Demographic transition}

This section studies the political economy of PAYG's adjustment to a negative fertility shock. It assumes that instantaneous population growth rate is reduced from $n$ to $m$ at time $t_{o}$.

Assumption 2 The population growth rate is

$$
\left\{\begin{array}{ll}
n & , \text { for } t \in\left(-\infty, t_{o}\right) \\
m & , \text { for } t \in\left[t_{o},+\infty\right)
\end{array} \text { with } n>m .\right.
$$

This shock produces a long transition period and the new steady state is achieved only at time $t_{o}+l .{ }^{5}$ Notice that the size of the transition period does not depend on the shock's size. During this demographic transition, the dependency rate is strictly increasing $\left(\dot{\rho}_{t}<0\right.$, for $\left.t \in\left(t_{o}, t_{o}+l\right)\right)$. If no reform is undertaken, then the PAYG per capita deficit is forever positive $\left(T_{t}(\emptyset)>0\right.$, for $\left.t>t_{o}\right)$ and strictly increasing during the demographic transition $\left(\dot{T}_{t}(\emptyset)>0\right.$, for $t \in\left(t_{o}, t_{o}+l\right)$, where $\emptyset$ stands for no reform). These properties of the pension system during the demographic transition are demonstrated in appendix A. Figure 3 illustrates the adjustment path of $\rho_{t}$ and $T_{t}$ during the demographic transition.

The results above shed some initial light on the problem of reforming PAYG during demographic transition. If we want a reform that eliminates PAYG's deficit at a given time $t_{1}$, then immediately after this reform $\left(\right.$ at $\left.t_{1}+\epsilon\right)$ the deficit would reappear. Similarly, if we want a reform that eliminates PAYG's deficit within a given time interval $\left[t_{1}, t_{2}\right]$, then PAYG budget necessarily would produce a superavit in the beginning of the interval and a deficit at its end.

\subsection{The reforms' set}

Confronted to an increasing dependency rate $\left(\dot{\rho}_{t}<0\right)$ agents may agree on reforming the PAYG system. The reforms' set include the full set of parametric reforms: increasing the contribution rate, increasing the retirement age and decreasing pension benefits.

\footnotetext{
${ }^{5}$ If one assumes a life expectancy of 80 years, this implies that the transition would take 80 years to accomplish.
} 


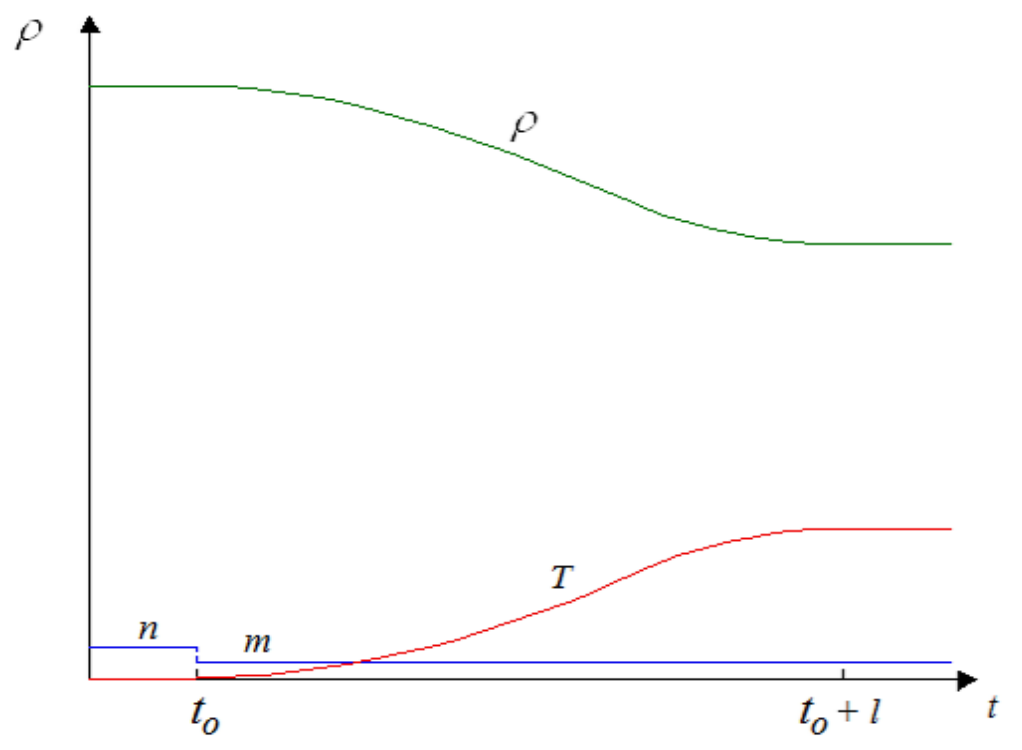

Figure 3: Demographic transition

Assumption 3 The reforms' set is

\begin{tabular}{|l|l|}
\hline Reform & Reform's content \\
\hline$\emptyset$ & No reform \\
\hline$A$ & Increase retirement $\boldsymbol{A}$ ge $(\uparrow$ a) \\
\hline$B$ & Reduce pension Benefits $(\downarrow b)$ \\
\hline$C$ & Increase Contribution rates $(\uparrow \tau)$ \\
\hline
\end{tabular}

Reform $\emptyset$ is the default outcome when agents do not agree on which reform to implement. In this case, the PAYG parameters remain the same and everyone, including the retirees, support its deficit. Reform $B$ reduces pension benefits for current and future retirees, it is equivalent to introducing a tax on pensions. Reforms $A$ and $C$ correspond respectively to an increase of the retirement age and of the contribution rate. ${ }^{6}$

Notice that the steady state problem had only two choice variables $(a, \tau)$ while the third PAYG parameter (b) was given by the budget-balanced condition (assumption 1). Now, there is one additional choice variable $(b)$ since the PAYG budget might be unbalanced.

\footnotetext{
${ }^{6}$ We assume in what follows that retirees do not go back to work when retirement is postponed. In other words, reform $A$ only applies to people working at the time of the reform.
} 
Reforms $A, B$ or $C$ reduce the deficit of the pension system. Nevertheless, the deficit starts growing again until the next steady state. The PAYG's deficit plays two roles in this model. First, as already mentioned before, it allows some imbalancement in PAYG budget before reform takes place, enabling the model to study the timing of the reform. Second, if we required the PAYG budget to be balanced at each time $t$, then it would be necessary to permanently and continuously reform PAYG during the demographic transition.

\subsection{Preferences over small reforms}

In this section, we consider marginal reforms of the pension system at time $t_{0}$, at which the fertility shock occurs. The following lemma, proven in the appendix, will be useful in analyzing these reforms.

Lemma 1 Denote $R_{r}(x)=-x u^{\prime \prime}(x) / u^{\prime}(x)$ the coefficient of relative risk aversion. ${ }^{7}$ Then:

$$
\partial\left(\frac{1}{1+\rho_{t}} u^{\prime}\left(1-\tau_{s s}-T_{t}\right)\right) / \partial t>0
$$

$$
\partial\left(\frac{\rho_{t}}{1+\rho_{t}} u^{\prime}\left(b_{s s}-T_{t}\right)\right) / \partial t\left\{\begin{array}{ll}
>0 & , \text { if } R_{r}(.)>1 \\
=0 & , \text { if } R_{r}(.)=1 \\
<0 & , \text { if } R_{r}(.)<1
\end{array} .\right.
$$

\subsubsection{Reducing pension benefits or increasing the contribution rate?}

We first compare reforms $B$ and $C$. The first reform consists in decreasing the benefit level from $b_{s s}$ to $b_{s s}-d b$ at time $t_{0}$ where $d b$ represents a marginal increment; the second reform consists in raising the payroll tax rate from $\tau_{s s}$ to $\tau_{s s}+d \tau$.

In the following proposition, we argue that any worker either prefers to increase the contribution rate or decrease the level of benefits, compared to the no reform case.

Lemma $2 A$ worker of age $x$ at $t_{0}$ either wants to decrease pension benefits or increase the payroll tax rate marginally. He cannot favor or reject both reforms at the same time.

\footnotetext{
${ }^{7}$ Admittedly, relative risk aversion is not the proper concept to use as there is no uncertainty in this model. One should however note that the coefficient of relative risk aversion corresponds to the elasticity of the marginal utility of consumption, which is more accurate in our framework. Abusing language, we shall continue to name this parameter relative risk aversion in the remainder of the paper.
} 


\section{Proof. See appendix.}

When the payroll tax rate is increased, individuals consume less during the working period. But they consume more during retirement as the income tax needed to balance the government budget is lowered. An increase in pension benefits also leads to more consumption during retirement. And it also leads to a drop in consumption during the working period, as it implies a higher income tax. Lemma 2 shows that the magnitude of these effects is exactly the same for reforms $B$ and $C$.

In the next lemma, we get more insight into the workers' preferences toward the reform.

Lemma 3 The marginal benefit of raising the contribution rate is increasing with worker's age if the coefficient of relative risk aversion is lower than 1.

Proof. See appendix.

When the payroll tax rate is increased, consumption in the working period is reduced. As older individuals spend less time working, they are less hurt by this effect. Moreover, consumption during retirement is increased. This benefit being declining over time $\left(\partial T_{t} / \partial \tau\right.$ decreases over time), older workers also tend to benefit more from this effect (when relative risk aversion is below 1, this is true even though they have a lower marginal utility of consumption (see lemma 1)).

Understanding that the retirees always benefit from an increase in the tax rate and, conversely, are hurt by a cut in benefits, we can draw on figure 4 the preferences for small reforms $B$ and $C$ of all the living individuals at time $t_{0}$ (when relative risk aversion is below 1).

It is clear from this figure that the preferences of the majority of the voters depend on the relative position of the median age individual and the individual indifferent between the two reforms. Recall that $x_{d}$ is the age of the decisive individuals in the steady state before the shock. We determine in the next proposition the preferences of individuals $x_{d}$ over reforms $B$ and $C$ when the initial steady state entails perfect consumption smoothing.

Proposition 3 Assume that $1-\tau_{s s}=b_{s s}$. Then, if the coefficient of relative risk aversion is below 1 , individuals $x_{d}$ favor a marginal decrease in pension benefits.

Proof. See appendix. 


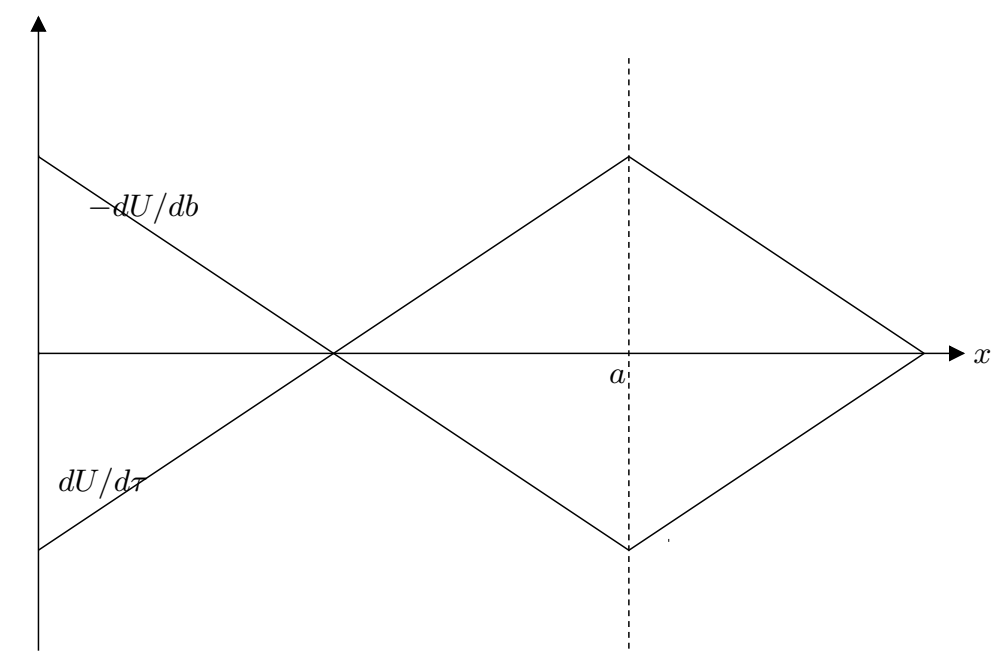

Figure 4: Welfare effects of reforms B and C

This result is somewhat surprising. It says that, when there is perfect consumption smoothing in the steady state before the shock, the decisive voter in this steady state prefers to cut benefits rather than to increase the payroll tax rate. This latter reform however generates a larger lifetime income than the former. To see this, consider a marginal increase in $\tau$ of size $d \tau$. An individual aged $x$ incur a loss of income equal to

$$
d \tau\left(a_{s s}-x\right)
$$

and a benefit

$$
d \tau \int_{t_{0}}^{t_{0}+l-x} \frac{\partial T_{v}}{\partial \tau} d v=d \tau \int_{t_{0}}^{t_{0}+l-x} \frac{\rho_{v}}{1+\rho_{v}} d v
$$

generating a net loss of income

$$
d \tau\left(a_{s s}-x-\int_{t_{0}}^{t_{0}+l-x} \frac{\rho_{v}}{1+\rho_{v}} d v\right) .
$$

On the other hand, when pension benefits are cut by an amount $d b$, the net loss of income is

$$
d b\left(l-a_{s s}-\int_{t_{0}}^{t_{0}+l-x} \frac{1}{1+\rho_{v}} d v\right) .
$$

With positive population growth, the lower bound on $\rho_{v}$ is $a_{s s} /\left(l-a_{s s}\right)$. Therefore

$$
d \tau\left(a_{s s}-x-\int_{t_{0}}^{t_{0}+l-x} \frac{\rho_{v}}{1+\rho_{v}} d v\right)<d \tau\left(\frac{a_{s s}}{l}-1\right) x \leq 0
$$


and

$$
d b\left(l-a_{s s}-\int_{t_{0}}^{t_{0}+l-x} \frac{1}{1+\rho_{v}} d v\right)>d b\left(l-a_{s s}\right) x \geq 0 .
$$

In words, reform $C$ generates an increase in lifetime income whereas reform $B$ leads to lower income. This does not however imply that individuals will favor such a reform over the status-quo, as proposition 3 demonstrates. The cost of this reform is that it may allocate consumption at different dates in an undesirable way for the individual. There is thus a trade-off between the increase in life-cycle income and the distortion of the consumption pattern. Proposition 3 shows that this trade-off is resolved in favor or reform $B$ for the individual decisive in the steady state (provided that it entails perfect consumption smoothing).

Note finally that proposition 3 holds when the coefficient of relative risk aversion is below 1. For a larger relative risk aversion, it may well be that the majority of the voters prefer reform $C$. In this case, the "higher income" effect of reform $C$ would dominate the misallocation of consumption over the life-cycle it induces.

We state in the following corollary the implications of proposition 3 for the preferences of the majority of the voters over the reform.

Corollary 1 Suppose that $x_{d}$ is larger than the median age at time $t_{0}, x_{m}$. Then, under the assumptions of proposition 3, the majority of the population vote for reform $B$.

Proof. If a marginal decrease in $b$ is beneficial to $x_{d}$, then, by lemma 3 , it is also beneficial to every younger worker. When $x_{d} \geq x_{m}$, this leads to the conclusion that the majority of the voters benefit from a marginal cut in benefits.

\subsubsection{Increasing the retirement age}

We now turn to the reform of the retirement age. Obviously, the retirees always favor an increase in the retirement age, as it allows to decrease the $\operatorname{tax} T$ at no cost for them.

Reform $A$ increases the retirement age from $a_{s s}$ to $a_{s s}+d a$ while keeping the contribution rate and pension benefits at their steady state level. To assess the effect of a marginal increase in $a$ at time $t_{0}$ on the life-cycle utility of a worker aged $x$, we differentiate (1) 
with respect to $a$ :

$$
\begin{gathered}
\frac{d U}{d a}=e^{-\beta\left(a_{s s}-x\right)}\left(u\left(1-\tau_{s s}-T_{t_{0}+a_{s s}-x}\right)-\gamma-u\left(b_{s s}-T_{t_{0}+a_{s s}-x}\right)\right) \\
-\left(\int_{t_{0}}^{t_{0}+a_{s s}-x} e^{-\beta\left(v-t_{0}\right)} \frac{\partial T_{v}}{\partial a} u^{\prime}\left(1-\tau_{s s}-T_{v}\right) d v+\int_{t_{0}+a_{s s}-x}^{t_{0}+l-x} e^{-\beta\left(v-t_{0}\right)} \frac{\partial T_{v}}{\partial a} u^{\prime}\left(b_{s s}-T_{v}\right) d v\right) .
\end{gathered}
$$

As far as the workers are concerned, the cost of increasing the retirement age, for $\tau$ and $b$ fixed at their steady state values, is $e^{-\beta\left(a_{s s}-x\right)}\left(u\left(1-\tau_{s s}-T\right)-\gamma-u\left(b_{s s}-T\right)\right)$. On the other hand, the benefit corresponds to the decrease in T. By differentiating (12) with respect to $x$, we evaluate how the net benefit for a worker of increasing the retirement age varies with age:

$$
\begin{aligned}
\frac{d^{2} U}{d x d a} & =\left(\dot{T}_{t_{0}+a_{s s}-x}+\frac{\partial T_{t_{0}+a_{s s}-x}}{\partial a}\right) e^{-\beta\left(a_{s s}-x\right)}\left(u^{\prime}\left(1-\tau_{s s}-T_{t_{0}+a_{s s}-x}\right)-u^{\prime}\left(b_{s s}-T_{t_{0}+a_{s s}-x}\right)\right) \\
& +\beta e^{-\beta\left(a_{s s}-x\right)}\left(u\left(1-\tau_{s s}-T_{t_{0}+a_{s s}-x}\right)-\gamma-u\left(b_{s s}-T_{t_{0}+a_{s s}-x}\right)\right) \\
& +\frac{\partial T_{t_{0}+l-x}}{\partial a} u^{\prime}\left(b_{s s}-T_{t_{0}+l-x}\right) .
\end{aligned}
$$

We shall continue to assume in this section that $1-\tau_{s s}=b_{s s}$. Under this assumption, the first term on the right hand side vanishes and the second one becomes $-\beta \gamma e^{-\beta\left(a_{s s}-x\right)}<0$. Noting that $\partial T_{t} / \partial a<0$ and thus that the last term is negative, we can conclude that $d^{2} U / d x d a$ is negative. This leads to the next lemma.

Lemma 4 Assume that $1-\tau_{s s}=b_{s s}$. The marginal benefit of postponing retirement is then decreasing with age.

This result is intuitive. It basically derives from the fact that younger individuals are farther away from retirement than older ones and therefore benefit from the decrease in the income tax caused by the reform for a longer time span.

We now want to sign expression (12). Consider an individual close to retirement at time $t_{0}\left(x\right.$ close to $\left.a_{s s}\right)$; for this individual, (12) becomes:

$$
\begin{aligned}
\frac{d U}{d a} & =u\left(1-\tau_{s s}-T_{t_{0}}\right)-\gamma-u\left(b_{s s}-T_{t_{0}}\right)-\int_{t_{0}}^{t_{0}+l-a_{s s}} e^{-\beta\left(v-t_{0}\right)} \frac{\partial T_{v}}{\partial a} u^{\prime}\left(b_{s s}-T_{v}\right) d v \\
& =u\left(1-\tau_{s s}\right)-\gamma-u\left(b_{s s}\right)-\int_{t_{0}}^{t_{0}+l-a_{s s}} e^{-\beta\left(v-t_{0}\right)} \frac{\partial T_{v}}{\partial a} u^{\prime}\left(b_{s s}-T_{v}\right) d v,
\end{aligned}
$$


where we have used the fact that $T_{t_{0}}=0$.

The retirement age in the steady state before the shock is given by (11). Using this condition yields:

$$
\frac{d U}{d a}=\frac{1}{\beta}\left(e^{-\beta\left(l-a_{s s}\right)}-1\right) u^{\prime}\left(b_{s s}\right) \tau_{s s} \frac{\partial \rho_{s s}}{\partial a}-\int_{t_{0}}^{t_{0}+l-a_{s s}} e^{-\beta\left(v-t_{0}\right)} \frac{\partial T_{v}}{\partial a} u^{\prime}\left(b_{s s}-T_{v}\right) d v .
$$

Using (19) in the appendix,

$$
\frac{\partial T_{t}}{\partial a}=-\tau_{s s} \frac{\partial \rho_{t}}{\partial a} \frac{1+\rho_{s s}}{\left(1+\rho_{t}\right)^{2}} .
$$

Differentiating (18) gives:

$$
\frac{\partial \rho_{t}}{\partial a}=n \frac{e^{n l}}{e^{n l}-e^{n a_{s s}}}\left(1+\rho_{t}\right)
$$

and therefore

$$
\frac{\partial T_{t}}{\partial a}=-\tau_{s s} n \frac{e^{n l}}{e^{n l}-e^{n a_{s s}}} \frac{1+\rho_{s s}}{\left(1+\rho_{t}\right)} .
$$

It thus appears that $\partial T_{t} / \partial a$ is increasing with $\rho_{t}$. As $\rho_{t}$ is decreasing over time, we have:

$$
0>\frac{\partial T_{t_{0}}}{\partial a}>\frac{\partial T_{t_{0}+l-a_{s s}}}{\partial a} .
$$

Moreover, $T_{t}$ is increasing over time. Therefore

$$
0<u^{\prime}\left(b_{s s}-T_{t_{0}}\right)<u^{\prime}\left(b_{s s}-T_{t_{0}+l-a_{s s}}\right) .
$$

These two inequalities imply that

$$
\int_{t_{0}}^{t_{0}+l-a_{s s}} e^{-\beta\left(v-t_{0}\right)} \frac{\partial T_{v}}{\partial a} u^{\prime}\left(b_{s s}-T_{v}\right) d v>-\frac{1}{\beta}\left(e^{-\beta\left(l-a_{s s}\right)}-1\right) \frac{\partial T_{t_{0}}}{\partial a} u^{\prime}\left(b_{s s}-T_{t_{0}}\right) .
$$

Observing that $T_{t_{0}}=0$ and

$$
\frac{\partial T_{t_{0}}}{\partial a}=-\tau_{s s} \frac{\partial \rho_{s s}}{\partial a} \frac{1}{\left(1+\rho_{s s}\right)},
$$

we thus have

$$
\frac{d U}{d a}<\frac{1}{\beta}\left(e^{-\beta\left(l-a_{s s}\right)}-1\right) u^{\prime}\left(b_{s s}\right) \tau_{s s} \frac{\partial \rho_{s s}}{\partial a}-\frac{1}{\beta}\left(e^{-\beta\left(l-a_{s s}\right)}-1\right) u^{\prime}\left(b_{s s}\right) \tau_{s s} \frac{\partial \rho_{s s}}{\partial a} \frac{1}{\left(1+\rho_{s s}\right)}<0 .
$$

It should be emphasized that we have used expression (18) for developing our argument and this expression is only valid for $t \leq t_{0}+a_{s s}$. Therefore this argument holds true as 


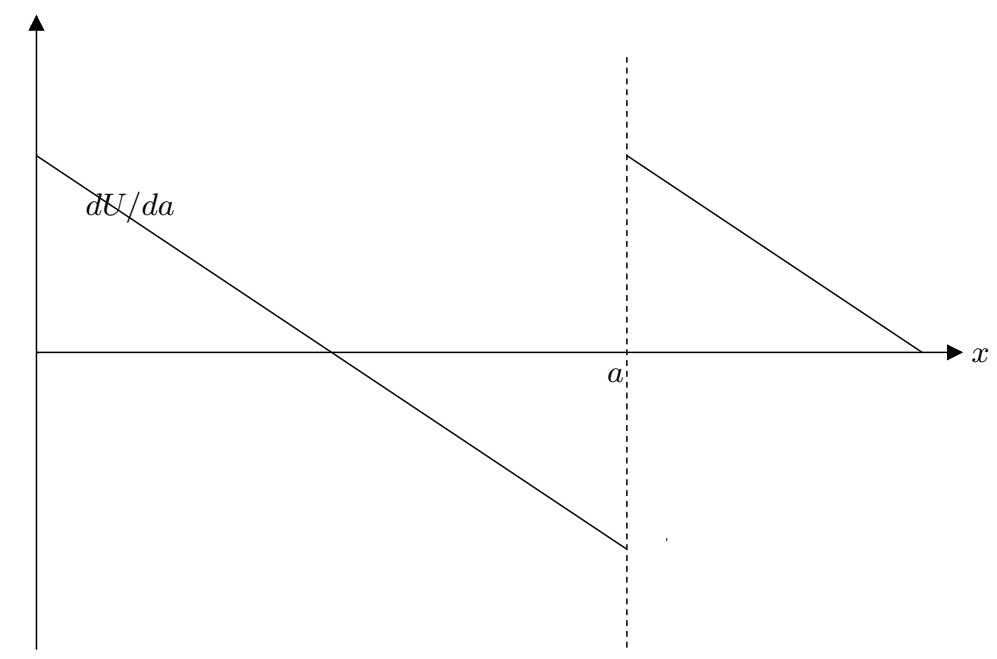

Figure 5: Welfare effects of reform A

long as $l-a_{s s}<a_{s s}$, which means that individuals spend more time working than on retirement. Under this assumption, we obtain the following proposition. ${ }^{8}$

Proposition 4 Assume $l-a_{s s}<a_{s s}$. Then the individuals close to retirement at $t_{0}$ are made worse-off by a marginal increase in the retirement age.

This proposition, combined with lemma 4, implies that the preferences toward reform $A$ of the living individuals at date $t_{0}$ can be represented as on figure 5 .

To get more insights with respect to the collective decision about the reform, we determine in the next proposition the preferences of individuals aged $x_{d}$ at the time of the reform, $t_{0}$.

Proposition 5 Assume that $1-\tau_{s s}=b_{s s}$. Then individuals $x_{d}$ benefit from a marginal increase in a at time $t_{0}$.

Proof. See appendix.

We thus have shown that individuals $x_{d}$ would vote for $A$ at time $t_{0}$. Strikingly, this result does not depend on the disutility of labor $\gamma$. Even when this latter is high would individuals aged $x_{d}$ want to increase the retirement age. This comes from the fact that the

\footnotetext{
${ }^{8}$ It can be shown that, when relative risk aversion is lower than 1 , this result extends to the case $t>t_{0}+a_{s s}$.
} 
retirement age is optimally chosen in the steady state. Accordingly, if they have a large disutility of labor, people choose to retire early in the steady state. Understanding this, proposition 5 shows that, following the demographic shock, the steady state decisive voter always prefers to increase the retirement age, thereby lowering the income tax needed to balance the PAYG budget, rather than keeping the parameters of the system unaltered and incurring larger deficits.

In the following corollary, we state the implication of proposition 5 for the majority preferences over reform $A$.

Corollary 2 Suppose that $x_{d}$ is larger than the median age at time $t_{0}, x_{m}$. Then, when $1-\tau_{s s}=b_{s s}$, the majority of the population vote for reform $A$.

Proof. Combine lemma 4 with proposition 5.

We have thus established a case for reform $A$. In the previous section, we have shown that the majority is also likely to vote for reform $B$ against the status quo. What about the comparison between $A$ and $B$ ? It turns out to be a difficult question with no clear analytical answer. We thus rely on numerical simulations (section 5) to get more insights about the comparison between these two reforms. But before we analyze in the next section how the timing of the reform affects its political support.

\subsection{Timing of the reform}

So far, the reform was assumed to take place at date $t_{0}$. We now consider the possibility that it happens at a later date $t>t_{0}$. We first investigate whether agents gain or lose from postponing the reforms. Then we analyze the evolution of the political support for each reform over time. We assume for simplicity in this section that the agents do not discount the future $(\beta=0)$.

\subsubsection{Costs and benefits of postponing the reforms}

In order to compute the benefit of postponing the reforms for a worker, we consider that each reform is approved at time $t \in\left(t_{0}, t_{0}+a_{s s}-x\right) .{ }^{9}$ The lifetime utility of a worker

\footnotetext{
${ }^{9}$ This assumption means that a worker at $t_{0}$ is still working at the time of the reform. This allows us to clearly distinguish between the preferences of workers and retirees.
} 
aged $x$ at $t_{0}$ when reform $C$ is approved at time $t$, after the shock and before he retires, is

$$
\begin{aligned}
U^{w}(x ; C, t)= & \int_{t_{0}}^{t}\left(u\left(1-\tau_{s s}-T_{v}(\emptyset)\right)-\gamma\right) d v+\int_{t}^{t_{0}+a_{s s}-x}\left(u\left(1-\tau_{s s}-\Delta \tau-T_{v}(C)\right)-\gamma\right) d v \\
& +\int_{t_{0}+a_{s s}-x}^{t_{0}+l-x} u\left(b_{s s}-T_{v}(C)\right) d v .
\end{aligned}
$$

The benefit of postponing reform $C$ is thus

$$
\frac{d U^{w}(x ; C, t)}{d t}=u\left(1-\tau_{s s}-T_{t}(\emptyset)\right)-u\left(1-\tau_{s s}-\Delta \tau-T_{t}(C)\right)>0 .
$$

Equation (15) shows that, when reform $C$ is postponed, the workers enjoy smaller contribution rates, $\tau_{s s}<\tau_{s s}+\Delta \tau$, but supports higher PAYG's deficit, $T_{t}(\emptyset)>T_{t}(C)$, both for a longer time span. The increase in the contribution rate is a transfer from the workers to everyone in the system. The compound effect of reform $C$ is thus negative during working time. ${ }^{10}$ It follows that postponing reform $C$ benefits the workers. However this hurts the retirees, since these agents do not support the increase in contribution but benefit from the deficit reduction.

The equivalent formulas for reform $B$ are

$$
\begin{aligned}
U^{w}(x ; B, t)= & \int_{t_{0}}^{t}\left(u\left(1-\tau_{s s}-T_{v}(\emptyset)\right)-\gamma\right) d v+\int_{t}^{t_{0}+a_{s s}-x}\left(u\left(1-\tau_{s s}-T_{v}(B)\right)-\gamma\right) d v \\
& +\int_{t_{0}+a_{s s}-x}^{t_{0}+l-x} u\left(b_{s s}-\Delta b-T_{v}(B)\right) d v
\end{aligned}
$$

and

$$
\frac{d U^{w}(x ; B, t)}{d t}=u\left(1-\tau_{s s}-T_{t}(\emptyset)\right)-u\left(1-\tau_{s s}-T_{t}(B)\right)<0 .
$$

Reform $B$ reduces the PAYG deficit and future pension benefits. Reducing benefits now or later does not change the worker's future benefits (as long as the reform is carried out before retiring). However, postponing reform $B$ delays the benefit of deficit reduction. Therefore, postponing reform $B$ hurts the workers. However, this benefits the retirees, since they will enjoy higher benefits for a longer time.

\footnotetext{
${ }^{10}$ Substitute $\tau_{t}$ by $\tau_{s s}$ into (19) to obtain $T_{t}(\emptyset)$. Substitute $\tau_{t}$ by $\tau_{s s}+\Delta \tau$ to obtain $T_{t}(C)$. Then, it is straightforward to show that $\tau_{s s}+\Delta \tau+T_{t}(C)>\tau_{s s}+T_{t}(\emptyset)$.
} 
The formulas for reform $A$ are

$$
\begin{aligned}
U^{w}(x ; A, t)= & \int_{t_{0}}^{t}\left(u\left(1-\tau_{s s}-T_{v}(\emptyset)\right)-\gamma\right) d v+\int_{t}^{t_{0}+a_{s s}+\Delta a-x}\left(u\left(1-\tau_{s s}-T_{v}(A)\right)-\gamma\right) d v \\
& +\int_{t_{0}+a_{s s}+\Delta a-x}^{t_{0}+l-x} u\left(b_{s s}-T_{v}(A)\right) d v
\end{aligned}
$$

and

$$
\frac{d U^{w}(x ; A, t)}{d t}=u\left(1-\tau_{s s}-T_{t}(\emptyset)\right)-u\left(1-\tau_{s s}-T_{t}(A)\right)<0 .
$$

Reform $A$ reduces the PAYG deficit and increases the retirement age. Similarly to reform $B$, increasing the retirement age now or later does not change the age at which the worker will retire (as long as reform is carried out before retiring). In the same way, postponing this reform delays the benefit of deficit reduction. As a consequence, postponing reform $A$ hurts the workers. It also hurts the retirees, for whom the benefit of deficit reduction is delayed.

Table 3 summarizes these effects. Is shows that, if reforms $A$ or $B$ are expected to happen somewhere in the near future, it is better for workers to carry them out at once than later on. However, delaying reform $C$ is beneficial. Concerning the retirees, the only reform worth postponing is the one that reduces their pension benefits.

Table 3: Effects of postponing reforms

$\begin{array}{lll}\text { Reform } & \text { Effect on workers } & \text { Effect on retirees } \\ A & - & - \\ B & - & + \\ C & + & -\end{array}$

\subsubsection{Evolution of the political support over time}

The implication of the results in the previous section on the evolution of the political support for the reforms over time is the following. Consider reform $B$ for example. The worker who is indifferent between reform $B$ and no reform at a given date $t$ is made worse-off when delaying this reform (and this is true by continuity for the workers just younger than him). Therefore, from this effect, the political support for $B$ is reduced if the reform is undertaken at date $t+d t$ instead of $t$. There is however another effect working in the opposite direction. Between dates $t$ and $t+d t$, some individuals are newly 
born. From lemma 3 and 2, we know that they favor $B$ over the status quo and thus that it tends to make the political support for this reform bigger. The same kinds of arguments can be developed for reforms $C$ and $A$.

Numerical examples in section 5 show that the net effect can be positive or negative, that is the political support for, say reform $B$, may increase or decrease with time. But before turning to these examples, we provide further analytical insights.

Let define $x_{t}^{i}, i=A, B, C$, as the age of the workers indifferent between implementing reform $i$ at date $t$ and no reform.

Using (21), evaluated at date $t$ with no discounting, $x_{t}^{C}$ is implicitly determined by solving

$$
\frac{d U}{d \tau}=\int_{t}^{t+a_{s s}-x_{t}^{C}}-\frac{1}{1+\rho_{v}} u^{\prime}\left(1-\tau_{s s}-T_{v}\right) d v+\int_{t+a_{s s}-x_{t}^{C}}^{t+l-x_{t}^{C}} \frac{\rho_{v}}{1+\rho_{v}} u^{\prime}\left(b_{s s}-T_{v}\right) d v=0
$$

Differentiating this equation with respect to $t$, we can determine how $x_{t}^{C}$ changes when reform $C$ is postponed marginally. The following lemma states a sufficient condition on the utility function for this variable to be increasing with the timing of the reform.

Lemma $5 x_{t}^{C}$ is increasing with $t$ if the coefficient of relative risk aversion is lower than 1 .

Proof. The differentiation of (17) leads to

$$
\begin{aligned}
& \dot{x}_{t}^{C}=\frac{\left(1 /\left(1+\rho_{t}\right)\right) u^{\prime}\left(1-\tau_{s s}-T_{t}\right)-\left(1 /\left(1+\rho_{t+a_{s s}-x_{t}^{C}}\right)\right) u^{\prime}\left(1-\tau_{s s}-T_{t+a_{s s}-x_{t}^{C}}\right)}{-d^{2} U / d x d \tau} \\
& +\frac{-\left(\rho_{t+a_{s s}-x_{t}^{C}} /\left(1+\rho_{t+a_{s s}-x_{t}^{C}}\right)\right) u^{\prime}\left(b_{s s}-T_{t+a_{s s}-x_{t}^{C}}\right)+\left(\rho_{t+l-x_{t}^{C}} /\left(1+\rho_{t+l-x_{t}^{C}}\right)\right) u^{\prime}\left(b_{s s}-T_{t+l-x_{t}^{C}}\right)}{-d^{2} U / d x d \tau}>0 .
\end{aligned}
$$

Lemma 1 implies that the numerator is negative and lemma 3 that the denominator is also negative, both when relative risk aversion is smaller than 1 . Note again that this is just a sufficient condition.

This lemma implies that the curve $d U / d \tau$ (resp. - $d U / d b)$ shifts downward (resp. upward) in figure 4. People who support reform $B$ are those younger than $x_{t}^{C}$, representing a proportion $F_{t}\left(x_{t}^{C}\right)$ of the total population. Symmetrically, by using lemma 2, the proportion of people supporting $C$ is $1-F_{t}\left(x_{t}^{C}\right)$. The variation with time of the political 
support for these reforms is thus given by

$$
\frac{\partial}{\partial t} F_{t}\left(x_{t}^{C}\right)=\dot{x}_{t}^{C} F_{t}^{\prime}\left(x_{t}^{C}\right)+\dot{F}_{t}\left(x_{t}^{C}\right)
$$

The first term on the right hand side captures the shift of the curve $-d U / d b$ as $t$ increases. From lemma 5 it is positive, meaning that the people who support reform $B$ are older and older as time goes on. However the second term is negative: due to population aging, the proportion of people younger than a given age is declining over time. These two effects are thus of opposite direction. The evolution over time of the political support for reforms $B$ and $C$ depends on which of the two dominates.

We now turn to reform $A$. Individuals $x_{t}^{A}$ are defined implicitly by the condition

$$
\begin{aligned}
\frac{d U}{d a}= & u\left(1-\tau_{s s}-T_{t+a_{s s}-x_{t}^{A}}\right)-\gamma-u\left(b_{s s}-T_{t+a_{s s}-x_{t}^{A}}\right) \\
& -\left(\int_{t}^{t+a_{s s}-x_{t}^{A}} \frac{\partial T_{v}}{\partial a} u^{\prime}\left(1-\tau_{s s}-T_{v}\right) d v+\int_{t+a_{s s}-x_{t}^{A}}^{t+l-x_{t}^{A}} \frac{\partial T_{v}}{\partial a} u^{\prime}\left(b_{s s}-T_{v}\right) d v\right)=0 .
\end{aligned}
$$

Differentiating this expression, we obtain:

$$
\begin{aligned}
\dot{x}_{t}^{A}= & -\dot{T}_{t+a_{s s}-x}\left(u^{\prime}\left(1-\tau_{s s}-T_{t+a_{s s}-x_{t}^{A}}\right)-u^{\prime}\left(b_{s s}-T_{t+a_{s s}-x_{t}^{A}}\right)\right) \\
& +\frac{\partial T_{t}}{\partial a} u^{\prime}\left(1-\tau_{s s}-T_{t}\right)-\frac{\partial T_{t+a_{s s}-x_{t}^{A}}}{\partial a} u^{\prime}\left(1-\tau_{s s}-T_{t+a_{s s}-x_{t}^{A}}\right) \\
& +\frac{\partial T_{t+a_{s s}-x_{t}^{A}}}{\partial a} u^{\prime}\left(b_{s s}-T_{t+a_{s s}-x_{t}^{A}}\right)-\frac{\partial T_{t+l-x_{t}^{A}}}{\partial a} u^{\prime}\left(b_{s s}-T_{t+l-x_{t}^{A}}\right) .
\end{aligned}
$$

It can be shown that the sum of the first three terms on the right hand side is negative. However, one can also show that the sum of the last two terms is positive. Therefore the sign of $\dot{x}_{t}^{A}$ is ambiguous.

\section{$5 \quad$ Numerical simulations}

We have performed several numerical simulations with a isoelastic utility function. Most of the theoretical results in the previous sections were obtained with perfect consumption smoothing in the steady state and a coefficient of relative risk aversion lower than 1 . The first aim of these simulations consists in checking the robustness of our results when there is not perfect consumption smoothing and relative risk aversion is larger than 1 . It turns 
out that the results in proposition 3 and corollary 1 continue to hold in this case: reform $B$ is majority preferred to reform $C$, unless the discount rate is very high and/or relative risk aversion is much larger than 1 . This is illustrated in the figure below, in which we have drawn the effect of reforms $B$ and $C$ on the median voter's utility. In the region with $\mathrm{a}+\left(\right.$ resp. - ), the reform is beneficial (resp. detrimental) to the median voter. ${ }^{11}$
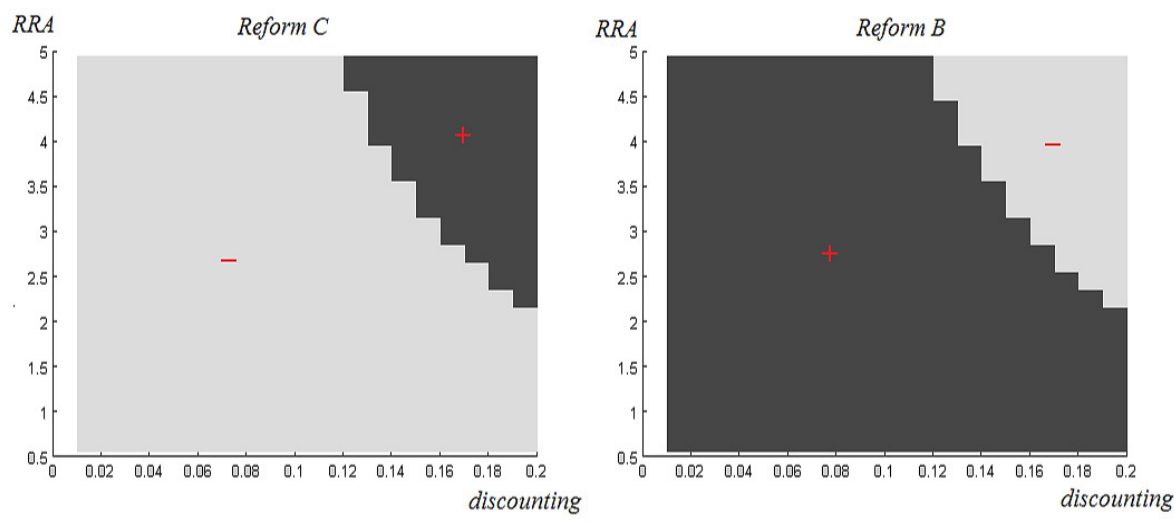

Figure 6: Effect of reforms $\mathrm{B}$ and $\mathrm{C}$ on the median voter

As far as reform $A$ is concerned, the numerical examples suggest that the political support for this reform is very high, this reform being majority preferred to reforms $B$ and $C$ in all the simulations. Moreover, when relative risk aversion is lower than 1 and there is no discounting, the political support for reforms $A$ and $B$ increases over time whereas the political support for $C$ is declining, except notably at the end of the transition

\footnotetext{
${ }^{11}$ It appears clearly from these figures that, when the coefficient of relative risk aversion is low enough, reform $C$ is majority preferred for any discount factor value lower than 0.2 . When individuals do not discount the future, one can show analytically that they choose to consume more during retirement than during working life: $1-\tau_{s s}<b_{s s}$. Only when the discount rate is high enough should they prefer to consume more when working. In the simulations summarized in figure 6 , the threshold value for the discount factor is around 0.1. At this point, there is perfect consumption smoothing in the steady state: $1-\tau_{s s}=b_{s s}$. These simulations therefore show that the analytical results derived in proposition 3 , that hold under perfect consumption smoothing and a coefficient of relative risk aversion lower than 1 , are robust to different parameters specifications.
} 
period. This is illustrated on the graph below, that shows the evolution of the political support for the three possible reforms over time.

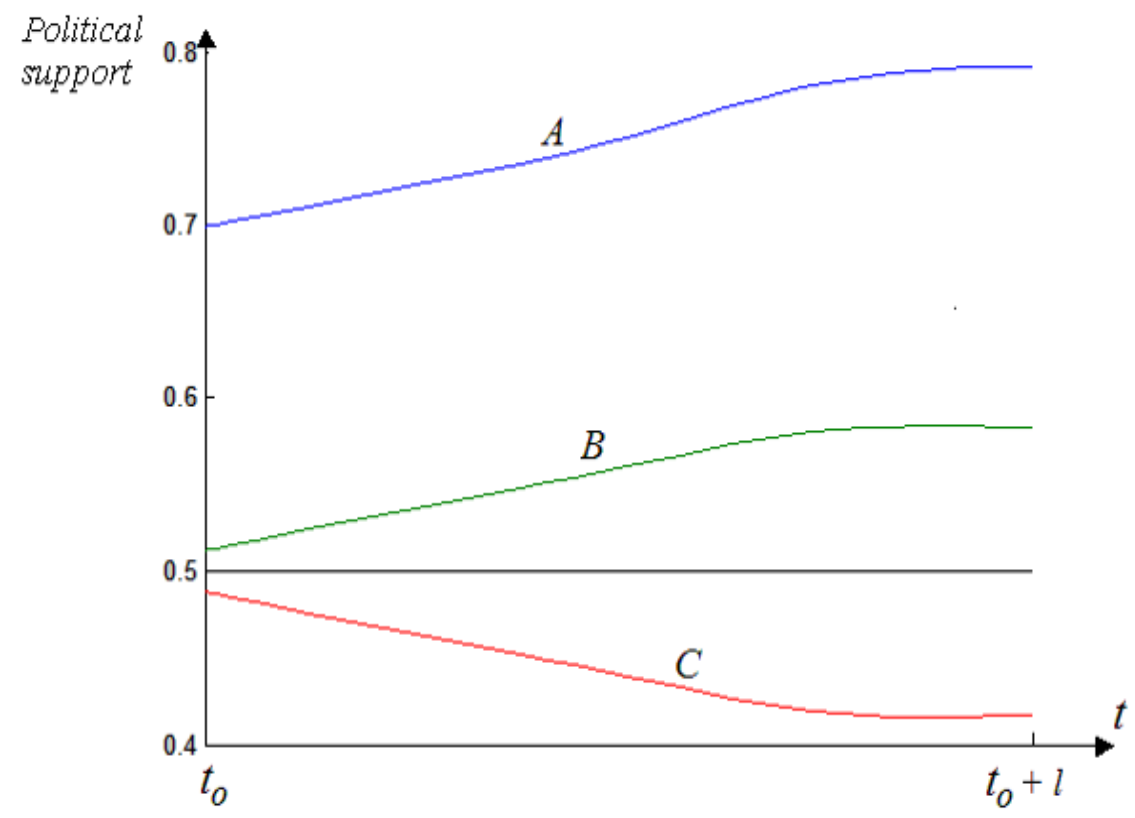

Figure 7: Evolution of the political support over time

\section{Conclusion}

This paper contributes to a better understanding of the political support for different parametric reforms of the PAYG pension system, when confronted to a downward fertility shock.

Its first contribution is about the effects of a downward fertility shock. This shock produces a long lasting demographic transition that takes a whole lifetime to accomplish. During this transition, the PAYG deficit steadily increases over time.

Our main results concern the preferences of the population toward the reforms. We have shown that the majority of the population is more likely to approve reform $B$ (cut in benefits) than reform $C$ (increase in the contribution rate). However, numerical simulations suggest that these two reforms are dominated (in the sense of receiving less political support) by reform $A$ (increase in the retirement age). This latter reform indeed garners 
the votes of a large fraction of the workers and of all the retirees. In these numerical simulations, we also observe that the political support for reforms $A$ and $B$ (resp. $C$ ) tends to increase (resp. decrease) over time.

This analysis relies on a number of simplifying assumptions, that should be relaxed in future research. Two extensions deserve a special attention. First, taxation of labor income does not create distortions in this model. One can guess that the political support for increasing the payroll tax rate would be undermined if such tax distortions were taken into account. Second, we assume no savings and this of course has an impact on the preferences of the agents toward the reform. We conjecture that introducing savings would modify the analysis in two main directions. On the one hand, this would allow individuals to better smooth their consumption across time. As the main drawback of reform $C$ is to constrain individuals in their consumption profile, the introduction of savings would make the political support for this reform more important. On the other hand, if one assumes that, after the demographic shock, the return from savings dominate the PAYG system, then people would like to make the PAYG system as small as possible. This effect would reinforce the political support for reform $B$. 


\section{Technical appendix}

\section{A Demographic transition}

1) We first show that a decrease in the fertility rate (of any magnitude) creates a transition period of length $l$. During this demographic transition, $\rho$ is strictly decreasing (the dependency rate is strictly increasing): $\dot{\rho}_{t}<0$, for $t \in\left(t_{o}, t_{o}+l\right)$.

Assumption 2 implies that the number of agents born at $t$ is

$$
\begin{cases}e^{n t} & , \text { from }-\infty \text { to } t_{o} \\ e^{n t_{o}} e^{m\left(t-t_{o}\right)} & , \text { from } t_{o} \text { to }+\infty\end{cases}
$$

a) Beginning of transition: $t \in\left[t_{0}, t_{0}+a\right]$

$$
\rho_{\text {begin }}(t) \equiv \frac{\int_{t-a}^{t_{o}} e^{n v} d v+e^{(n-m) t_{o}} \int_{t_{o}}^{t} e^{m v} d v}{\int_{t-l}^{t-a} e^{n v} d v}=\frac{e^{n t_{o}-n t}-e^{-n a}+\frac{n}{m} e^{n t_{o}-n t}\left(e^{m\left(t-t_{o}\right)}-1\right)}{e^{-n a}-e^{-n l}} .
$$

To prove that $\rho_{\text {begin }}$ is decreasing:

$$
\dot{\rho}_{\text {begin }}(t)=\frac{e^{n t_{o}-n t}\left(\left(\frac{n m-n^{2}}{m}\right)\left(e^{m\left(t-t_{o}\right)}-1\right)-n\right)}{e^{-n a}-e^{-n l}}<0 .
$$

b) End of transition: $t \in\left[t_{0}+a, t_{0}+l\right]$

$$
\begin{aligned}
\rho_{\text {end }}(t) & \equiv \frac{e^{(n-m) t_{o}} \int_{t-a}^{t} e^{m v} d v}{\int_{t-l}^{t_{o}} e^{n v} d v+e^{(n-m) t_{o}} \int_{t_{o}}^{t-a} e^{m v} d v} \\
& =\frac{e^{n t_{o}}\left(1-e^{-m a}\right)}{\frac{m}{n}\left(e^{n t_{o}-m t+m t_{o}}-e^{n(t-l)-m t+m t_{o}}\right)+e^{n t_{o}}\left(e^{-m a}-e^{-m t+m t_{o}}\right)} .
\end{aligned}
$$

To prove that $\rho_{\text {end }}$ is decreasing:

$\dot{\rho}_{\text {end }}(t)=\frac{-e^{n t_{o}}\left(1-e^{-m a}\right)\left(\frac{m}{n}\left(-m e^{n t_{o}-m t+m t_{o}}-(n-m) e^{n(t-l)-m t+m t_{o}}\right)+m e^{n t_{o}-m t+m t_{o}}\right)}{\left(\frac{m}{n}\left(e^{n t_{o}-m t+m t_{o}}-e^{n(t-l)-m t+m t_{o}}\right)+e^{n t_{o}}\left(e^{-m a}-1\right)\right)^{2}}$. 
Multiplying by $n / m$ gives

$$
\frac{-e^{n t_{o}}\left(1-e^{-m a}\right)(n-m) e^{m t_{o}-m t}\left(e^{n t_{o}}-e^{n(t-l)}\right)}{\frac{n}{m}\left(\frac{m}{n}\left(e^{n t_{o}-m t+m t_{o}}-e^{n(t-l)-m t+m t_{o}}\right)+e^{n t_{o}}\left(e^{-m a}-1\right)\right)^{2}}<0 .
$$

c) New steady-state

$$
\rho_{n s s}(t) \equiv \frac{e^{(n-m) t_{o}} \int_{t-a}^{t} e^{m v} d v}{e^{(n-m) t_{o}} \int_{t-l}^{t-a} e^{m v} d v}=\frac{\left(\frac{e^{m t}-e^{m(t-a)}}{m}\right)}{\left(\frac{e^{m(t-a)}-e^{m(t-l)}}{m}\right)}=\frac{1-\frac{1}{e^{m a}}}{\frac{1}{e^{m a}}-\frac{1}{e^{m l}}} .
$$

2) We now prove that, if no reform is undertaken, then the PAYG per capita deficit is forever positive and strictly increasing during the demographic transition: $T_{t}(\emptyset)>0$, for $t>t_{o} ; \dot{T}_{t}(\emptyset)>0$, for $t \in\left(t_{o}, t_{o}+l\right)$, where $\emptyset$ stands for no reform.

Solving (3) for $T_{t}$ and using the equalities $\left(N_{t}^{w}+N_{t}^{r}\right) / N_{t}^{r}=1+\rho_{t}$ and $\left(N_{t}^{w}+N_{t}^{r}\right) / N_{t}^{w}=$ $\left(1+\rho_{t}\right) / \rho_{t}$ gives

$$
T_{t}=\frac{1}{1+\rho_{t}} b_{t}-\frac{\rho_{t}}{1+\rho_{t}} \tau_{t}
$$

Substituting the steady state pension and contribution rate gives

$$
T_{t}(\emptyset)=\frac{\rho_{s s}-\rho_{t}}{1+\rho_{t}} \tau_{s s}
$$

Recalling that $\rho_{s s}>\rho_{t}$, we obtain that $T_{t}(\emptyset)>0, \forall t>t_{o}$.

We then compute $\dot{T}_{t}(\emptyset)$ :

$$
\dot{T}_{t}(\emptyset)=-\frac{\dot{\rho}_{t}\left(1+\rho_{t}\right)+\left(\rho_{s s}-\rho_{t}\right) \dot{\rho}_{t}}{\left(1+\rho_{t}\right)^{2}} \tau_{s s} .
$$

Using our previous results on the evolution of the dependency rate, this is positive.

\section{B Proof of lemma 1}

Use (19) to substitute $1-\tau_{s s}-T_{t}=1-\tau_{s s}\left(1+\rho_{s s}\right) /\left(1+\rho_{t}\right)$ into $u^{\prime}\left(1-\tau_{s s}-T_{t}\right)$. Differentiating:

$$
\begin{aligned}
& \frac{\partial\left(1 /\left(1+\rho_{t}\right)\right) u^{\prime}\left(1-\tau_{s s}-T_{t}\right)}{\partial t} \\
= & -\frac{\dot{\rho}_{t}}{\left(1+\rho_{t}\right)^{2}}\left(u^{\prime}\left(1-\frac{1+\rho_{s s}}{1+\rho_{t}} \tau_{s s}\right)-\frac{1}{1+\rho_{t}}\left(1+\rho_{s s}\right) \tau_{s s} u^{\prime \prime}\left(1-\frac{1+\rho_{s s}}{1+\rho_{t}} \tau_{s s}\right)\right)>0 .
\end{aligned}
$$


Use (19) to substitute $b_{s s}-T_{t}=\left(\rho_{t} /\left(1+\rho_{t}\right)\right) \tau_{s s}\left(1+\rho_{s s}\right)$ into $u^{\prime}\left(b_{s s}-T_{t}\right)$. Differentiating:

$$
\begin{aligned}
& \frac{\partial\left(\rho_{t} /\left(1+\rho_{t}\right)\right) u^{\prime}\left(b_{s s}-T_{t}\right)}{\partial t} \\
= & \frac{\dot{\rho}_{t}}{\left(1+\rho_{t}\right)^{2}}\left(u^{\prime}\left(\frac{\rho_{t}}{1+\rho_{t}} \tau_{s s}\left(1+\rho_{s s}\right)\right)+\frac{\rho_{t}}{1+\rho_{t}} \tau_{s s}\left(1+\rho_{s s}\right) u^{\prime \prime}\left(\frac{\rho_{t}}{1+\rho_{t}} \tau_{s s}\left(1+\rho_{s s}\right)\right)\right) .
\end{aligned}
$$

The expression above is positive (negative) if the coefficient of relative risk aversion is greater (lower) than 1 .

\section{Proof of lemma 2}

From (1), the lifetime utility of a worker aged $x$ at $t_{0}$ under no reform is:

$$
U_{t_{0}}^{w}(x)=\int_{t_{0}}^{t_{0}+a_{s s}-x} e^{-\beta\left(v-t_{0}\right)}\left(u\left(1-\tau_{s s}-T_{v}\right)-\gamma\right) d v+\int_{t_{0}+a_{s s}-x}^{t_{0}+l-x} e^{-\beta\left(v-t_{0}\right)} u\left(b_{s s}-T_{v}\right) d v .
$$

The effect of a marginal increase of the payroll tax rate on his utility is

$\frac{d U}{d \tau}(x)=\int_{t_{0}}^{t_{0}+a_{s s}-x} e^{-\beta\left(v-t_{0}\right)}\left(-1-\frac{\partial T_{v}}{\partial \tau}\right) u^{\prime}\left(1-\tau_{s s}-T_{v}\right) d v+\int_{t_{0}+a_{s s}-x}^{t_{0}+l-x} e^{-\beta\left(v-t_{0}\right)}\left(-\frac{\partial T_{v}}{\partial \tau}\right) u^{\prime}\left(b_{s s}-T_{v}\right) d v$

From (19):

and thus

$$
\frac{\partial T_{v}}{\partial \tau}=-\frac{\rho_{v}}{1+\rho_{v}}
$$

$\frac{d U}{d \tau}(x)=\int_{t_{0}}^{t_{0}+a_{s s}-x} e^{-\beta\left(v-t_{0}\right)}\left(-\frac{1}{1+\rho_{v}}\right) u^{\prime}\left(1-\tau_{s s}-T_{v}\right) d v+\int_{t_{0}+a_{s s}-x}^{t_{0}+l-x} e^{-\beta\left(v-t_{0}\right)} \frac{\rho_{v}}{1+\rho_{v}} u^{\prime}\left(b_{s s}-T_{v}\right) d v$.

To determine the impact of a marginal decrease in pension benefits, we note that, from (19),

and compute:

$$
\frac{\partial T_{v}}{\partial b}=\frac{1}{1+\rho_{v}}
$$

$$
\begin{aligned}
\frac{d U}{d b}(x) & =\int_{t_{0}}^{t_{0}+a_{s s}-x} e^{-\beta\left(v-t_{0}\right)}\left(-\frac{\partial T_{v}}{\partial b}\right) u^{\prime}\left(1-\tau_{s s}-T_{v}\right) d v+\int_{t_{0}+a_{s s}-x}^{t_{0}+l-x} e^{-\beta\left(v-t_{0}\right)}\left(1+\frac{\partial T_{v}}{\partial b}\right) u^{\prime}\left(b_{s s}-T_{v}\right) d v \\
& =\int_{t_{0}}^{t_{0}+a_{s s}-x} e^{-\beta\left(v-t_{0}\right)}\left(-\frac{1}{1+\rho_{v}}\right) u^{\prime}\left(1-\tau_{s s}-T_{v}\right) d v+\int_{t_{0}+a_{s s}-x} e^{-\beta\left(v-t_{0}\right)} \frac{\rho_{v}}{1+\rho_{v}} u^{\prime}\left(b_{s s}-T_{v}\right) d v
\end{aligned}
$$

The two expressions for $d U(x) / d \tau$ and $d U(x) / d b$ are identical. Hence the result. 


\section{Proof of lemma 3}

Differentiating $d U / d \tau$ (given in $(21)$ ) with respect to $x$, we obtain

$$
\begin{aligned}
\frac{d^{2} U}{d x d \tau} & =\frac{d}{d x}\left(\int_{t_{0}}^{t_{0}+a_{s s}-x} e^{-\beta\left(v-t_{0}\right)}\left(-\frac{1}{1+\rho_{v}}\right) u^{\prime}\left(1-\tau_{s s}-T_{v}\right) d v+\int_{t_{0}+a_{s s}-x}^{t_{0}+l-x} e^{-\beta\left(v-t_{0}\right)} \frac{\rho_{v}}{1+\rho_{v}} u^{\prime}\left(b_{s s}-T_{v}\right) d v\right) \\
& =\frac{e^{-\beta\left(a_{s s}-x\right)}}{1+\rho_{t_{0}+a_{s s}-x}} u^{\prime}\left(1-\tau_{s s}-T_{t_{0}+a-x}\right) \\
& +\frac{\rho_{t_{0}+a_{s s}-x}}{1+\rho_{t_{0}+a_{s s}-x}} e^{-\beta\left(a_{s s}-x\right)} u^{\prime}\left(b_{s s}-T_{t_{0}+a_{s s}-x}\right)-e^{-\beta(l-x)} \frac{\rho_{t_{0}+l-x}}{1+\rho_{t_{0}+l-x}} u^{\prime}\left(b_{s s}-T_{t_{0}+l-x}\right) .
\end{aligned}
$$

By lemma 1 and noting that $e^{-\beta\left(a_{s s}-x\right)}>e^{-\beta(l-x)}$, the difference between the two last terms is positive for a relative risk aversion lower than 1. This condition is thus sufficient for having $d^{2} U / d x d \tau>0$.

\section{E $\quad$ Proof of proposition 3}

We write (21) for the individual aged $x_{d}$ :

$\frac{d U}{d \tau}=\int_{t_{0}}^{t_{0}+a_{s s}-x_{d}} e^{-\beta\left(v-t_{0}\right)}\left(-\frac{1}{1+\rho_{v}}\right) u^{\prime}\left(1-\tau_{s s}-T_{v}\right) d v+\int_{t_{0}+a_{s s}-x_{d}}^{t_{0}+l-x_{d}} e^{-\beta\left(v-t_{0}\right)} \frac{\rho_{v}}{1+\rho_{v}} u^{\prime}\left(b_{s s}-T_{v}\right) d v$

When $1-\tau_{s s}=b_{s s}$,

$$
\frac{u^{\prime}\left(1-\tau_{s s}-T_{v}\right)}{u^{\prime}\left(b_{s s}-T_{v}\right)}=\frac{u^{\prime}\left(1-\tau_{s s}\right)}{u^{\prime}\left(b_{s s}\right)}=1
$$

As $x_{d}$ obtains his optimal contribution rate in the steady state, we have from (9):

$$
\frac{u^{\prime}\left(1-\tau_{s s}\right)}{u^{\prime}\left(b_{s s}\right)}=\frac{e^{-\beta\left(l-x_{d}\right)}-e^{-\beta\left(a_{s s}-x_{d}\right)}}{e^{-\beta\left(a_{s s}-x_{d}\right)}-1} \rho_{s s} .
$$

Coming back to the expression for $d U / d \tau$ and substituting the previous relationships, we have

$$
\begin{aligned}
& \frac{d U}{d \tau}= \\
& \frac{e^{-\beta\left(l-x_{d}\right)}-e^{-\beta\left(a_{s s}-x_{d}\right)}}{e^{-\beta\left(a_{s s}-x_{d}\right)}-1} \int_{t_{0}}^{t_{0}+a_{s s}-x_{d}} e^{-\beta\left(v-t_{0}\right)}\left(-\frac{\rho_{s s}}{1+\rho_{v}}\right) u^{\prime}\left(b_{s s}-T_{v}\right) d v+\int_{t_{0}+a_{s s}-x_{d}}^{t_{0}+l-x_{d}} e^{-\beta\left(v-t_{0}\right)} \frac{\rho_{v}}{1+\rho_{v}} u^{\prime}\left(b_{s s}-T_{v}\right) d v \\
& <\frac{e^{-\beta\left(l-x_{d}\right)}-e^{-\beta\left(a_{s s}-x_{d}\right)}}{e^{-\beta\left(a_{s s}-x_{d}\right)}-1} \int_{t_{0}+a_{s s}-x_{d}}^{t_{0}+l-x_{d}} e^{-\beta\left(v-t_{0}\right)}\left(-\frac{\rho_{v}}{1+\rho_{v}}\right) u^{\prime}\left(b_{s s}-T_{v}\right) d v+\int_{t_{0}+a_{s s}-x_{d}}^{-\beta\left(v-t_{0}\right)} \frac{\rho_{v}}{1+\rho_{v}} u^{\prime}\left(b_{s s}-T_{v}\right) d v,
\end{aligned}
$$


where we have used the fact that $\rho_{s s}>\rho_{v}$.

Using lemma 1, we have that, when relative risk aversion is lower than 1 ,

$$
\begin{aligned}
-\frac{\rho_{v}}{1+\rho_{v}} u^{\prime}\left(b_{s s}-T_{v}\right) & <-\frac{\rho_{t+a_{s s}-x_{d}}}{1+\rho_{t+a_{s s}-x_{d}}} u^{\prime}\left(b_{s s}-T_{t+a_{s s}-x_{d}}\right), \forall v<t+a_{s s}-x_{d} \\
\frac{\rho_{v}}{1+\rho_{v}} u^{\prime}\left(b_{s s}-T_{v}\right) & <\frac{\rho_{t+a_{s s}-x_{d}}}{1+\rho_{t+a_{s s}-x_{d}}} u^{\prime}\left(b_{s s}-T_{t+a_{s s}-x_{d}}\right), \forall v>t+a_{s s}-x_{d}
\end{aligned}
$$

and thus

$$
\begin{aligned}
\frac{d U}{d \tau} & <\left(e^{-\beta\left(l-x_{d}\right)}-e^{-\beta\left(a_{s s}-x_{d}\right)}\right)\left(-\frac{\rho_{t+a_{s s}-x_{d}}}{1+\rho_{t+a_{s s}-x_{d}}} u^{\prime}\left(b_{s s}-T_{t+a_{s s}-x_{d}}\right)\right) \\
& +\left(e^{-\beta\left(l-x_{d}\right)}-e^{-\beta\left(a_{s s}-x_{d}\right)}\right) \frac{\rho_{t+a_{s s}-x_{d}}}{1+\rho_{t+a_{s s}-x_{d}}} u^{\prime}\left(b_{s s}-T_{t+a_{s s}-x_{d}}\right)=0 .
\end{aligned}
$$

\section{F Proof of proposition 5}

We rewrite (12) for the individual $x_{d}$ :

$$
\begin{aligned}
\frac{d U}{d a}= & e^{-\beta\left(a_{s s}-x_{d}\right)}\left(u\left(1-\tau_{s s}-T_{t_{0}+a_{s s}-x_{d}}\right)-\gamma-u\left(b_{s s}-T_{t_{0}+a_{s s}-x_{d}}\right)\right) \\
& -\left(\int_{t_{0}}^{t_{0}+a_{s s}-x_{d}} e^{-\beta\left(v-t_{0}\right)} \frac{\partial T_{v}}{\partial a} u^{\prime}\left(1-\tau_{s s}-T_{v}\right) d v+\int_{t_{0}+a_{s s}-x_{d}}^{t_{0}+l-x_{d}} e^{-\beta\left(v-t_{0}\right)} \frac{\partial T_{v}}{\partial a} u^{\prime}\left(b_{s s}-T_{v}\right) d v\right) .
\end{aligned}
$$

Under the assumption that $1-\tau_{s s}=b_{s s}$ and making use of (11), it becomes:

$$
\frac{d U}{d a}=\frac{1}{\beta}\left(e^{-\beta\left(l-a_{s s}\right)}-1\right) u^{\prime}\left(b_{s s}\right) \tau_{s s} \frac{\partial \rho_{s s}}{\partial a}-\int_{t_{0}}^{t_{0}+l-x_{d}} e^{-\beta\left(v-t_{0}\right)} \frac{\partial T_{v}}{\partial a} u^{\prime}\left(b_{s s}-T_{v}\right) d v .
$$

From (14):

$$
\frac{\partial T_{v}}{\partial a}=-\tau_{s s} n \frac{e^{n l}}{e^{n l}-e^{n a_{s s}}} \frac{1+\rho_{s s}}{\left(1+\rho_{v}\right)} .
$$

Recalling that $\rho_{v}<\rho_{s s}$, this implies:

$$
-\frac{\partial T_{v}}{\partial a}>\tau_{s s} n \frac{e^{n l}}{e^{n l}-e^{n a_{s s}}} .
$$

Noting that $u^{\prime}\left(b_{s s}-T_{v}\right)>u^{\prime}\left(b_{s s}\right)$, we obtain

$$
\begin{aligned}
\frac{d U}{d a}> & \frac{1}{\beta}\left(e^{-\beta\left(l-x_{d}\right)}-e^{-\beta\left(a_{s s}-x_{d}\right)}\right) u^{\prime}\left(b_{s s}\right) \tau_{s s} n e^{n a_{s s}} e^{n l} \frac{e^{n l}-1}{\left(e^{n l}-e^{n a_{s s}}\right)^{2}} \\
& -\frac{1}{\beta}\left(e^{-\beta\left(l-x_{d}\right)}-1\right) u^{\prime}\left(b_{s s}\right) \tau_{s s} n \frac{e^{n l}}{e^{n l}-e^{n a_{s s}}} .
\end{aligned}
$$


We then make use of the fact that $x_{d}$ is decisive in the steady state and thus obtains his optimal contribution rate. Using (9) with the assumption $1-\tau_{s s}=b_{s s}$, we obtain:

$$
\begin{aligned}
e^{-\beta\left(l-x_{d}\right)}-e^{-\beta\left(a_{s s}-x_{d}\right)} & =\frac{1}{\rho_{s s}}\left(e^{-\beta\left(a_{s s}-x_{d}\right)}-1\right) \\
& =\frac{e^{n l}-e^{n a_{s s}}}{e^{n l}\left(e^{n a_{s s}}-1\right)}\left(e^{-\beta\left(a_{s s}-x_{d}\right)}-1\right) \\
\Leftrightarrow e^{-\beta\left(l-x_{d}\right)}-1 & =\left(e^{-\beta\left(a_{s s}-x_{d}\right)}-1\right) \frac{e^{n a_{s s}}}{e^{n l}} \frac{e^{n l}-1}{e^{n a_{s s}}-1} .
\end{aligned}
$$

Substituting into (23):

$$
\frac{d U}{d a}>\frac{1}{\beta} u^{\prime}\left(b_{s s}\right) \tau_{s s} n\left(e^{-\beta\left(a_{s s}-x_{d}\right)}-1\right)\left(\frac{e^{n a_{s s}}}{e^{n l}-e^{n a_{s s}}} \frac{e^{n l}-1}{e^{n a_{s s}}-1}-\frac{e^{n a_{s s}}}{e^{n l}-e^{n a_{s s}}} \frac{e^{n l}-1}{e^{n a_{s s}}-1}\right)=0 .
$$




\section{References}

[1] Boldrin, M., M. De Nardi and L. Jones, 2005. Fertility and Social Security. NBER Working Paper 11146.

[2] Breyer, F. and K. Stolte, 2001. Demographic Change, Endogenous Labor Supply and the Political Feasibility of Pension Reform. Journal of Population Economics, 14, 409-24.

[3] Browning, E., 1975. Why the Social Insurance Budget Is Too Large in a Democratic Society. Economic Inquiry, 13, 373-88.

[4] Conesa, J. and D. Krueger, 1999. Social Security Reform with Heterogeneous Agents. Review of Economic Dynamics, 2, 757-95.

[5] Conesa, J. and C. Garriga, 2008a. Optimal Response to a Transitory Demographic Shock. in De Menil, G., Fenge, R., Pestieau, P., eds. Pension Strategies in Europe and the United States, CESifo - MIT Press.

[6] Conesa, J. and C. Garriga, 2008b. Optimal Fiscal Policy in the Design of Social Security Reforms. International Economic Review, 49, 291-318.

[7] Crawford, V. and D. Lilien, 1981. Social Security and the Retirement Decision. Quarterly Journal of Economics, 96, 505-29.

[8] Cremer, H. and P. Pestieau, 2000. Reforming our Pension System: Is It a Demographic, Financial or Political Problem? European Economic Review, 44, 974-83.

[9] De Nardi, M., S. Imrohoroglu and T. Sargent, 1999. Projected U.S. Demographics and Social Security. Review of Economic Dynamics, 2, 575-615.

[10] Galasso, V. and P. Profeta, 2002. The Political Economy of Social Security: A Survey. European Journal of Political Economy, 18, 1-29.

[11] Gonzalez-Eiras, M. and D. Niepelt, 2008. The Future of Social Security. Journal of Monetary Economics, 55, 197-218. 
[12] Gruber, J. and D. Wise, 1998. Social Security and Retirement: An International Comparison. American Economic Review, Vol. 88, No. 2, Papers and Proceedings of the Hundred and Tenth Annual Meeting of the American Economic Association, 158-63.

[13] Lacomba, J. and F. Lagos, 2007. Political Election on Legal Retirement Age. Social Choice and Welfare, 29, 1-17.

[14] Nishiyama, S. and K. Smetters, 2007. Does Social Security Privatization Produce Efficiency Gains? Quarterly Journal of Economics, 122, 1677-1719.

[15] Sheshinski, E., 1978, A Model of Social Security and Retirement Decisions. Journal of Public Economics, 10, 337-60.

[16] Sjoblom, K., 1985. Voting for Social Security. Public Choice, 45, 225-40. 